\title{
HISTÓRIA DA QUÍMICA: UMA ANÁLISE SOBRE A PRESENÇA DO CONTEÚDO NOS PNLDS DE 2015 E 2018
}

\author{
HISTORIA DE LA QUÍMICA: UN ANÁLISIS SOBRE LA PRESENCIA DE \\ CONTENIDO EN LOS PNLD de 2015 Y 2018
}

\section{HISTORY OF CHEMISTRY: AN ANALYSIS ON THE PRESENCE OF CONTENT IN THE PNLDs OF 2015 AND 2018}

\section{DOI: 10.22481/rbba.v10i02.9713}

Antônio de Pádua Arruda dos Santos Filho Instituto Federal de Educação, Ciência e Tecnologia do Ceará, Fortaleza, Ceará, Brasil

ORCID: https://orcid.org/0000-0002-3263-6973

ID Lattes: http://lattes.cnpq.br/7808055468042546 Endereço eletrônico: apasf95@hotmail.com

Maria Cleide da Silva Barroso Instituto Federal de Educação, Ciência e Tecnologia do Ceará, Brasil

ORCID: https://orcid.org/0000-0001-5577-9523

ID Lattes: http://lattes.cnpq.br/6267402154400258 Endereço eletrônico: ccleideifcemaraca@gmail.com

Caroline de Goes Sampaio Instituto Federal de Educação, Ciência e Tecnologia, Maracanaú, Ceará, Brasil ORCID: https://orcid.org/0000-0002-3642-234X ID Lattes: http://lattes.cnpq.br/9870299456044346 Endereço eletrônico: carol-quimica@ hotmail.com

\section{RESUMO}

Pesquisas evidencia que as reformas curriculares que estão acontecendo na educação brasileira deixam o ensino empobrecido, consequentemente os livros didáticos. Diante disso, o presente artigo tem o objetivo de analisar como o 
conteúdo de História da Química tem sido abordado nas versões e um e dois, do livro didático Química, da autora Martha Reis, que fizeram parte do PNLD dos anos de 2015 e 2018. Para isso, foi realizada uma Revisão Sistemática de Literatura, para ver o que outros pesquisadores da área tem argumentado sobre a importância da HQ no ensino de Química, um estudo documental analisando o que os PCNs, a BNCC e o PNLD têm falado sobre a HQ, e por fim, uma análise das duas versões dos livros didáticos descritos anteriormente. Observou-se que de uma edição para outra, os livros sofreram algumas alterações, principalmente nos volumes dois e três. Por essa razão, sugestiona-se que sejam realizados mais estudos nessa área, analisando sobretudo outros livros didáticos de química.

Palavras-chave: História da Química. Ensino de Química. Livro didático. PNLD. Martha Reis.

\section{RESUMEN}

La investigación muestra que las reformas curriculares que están ocurriendo en la educación brasileña dejan la educación empobrecida, en consecuencia, los libros de texto. Por ello, este artículo pretende analizar cómo se ha abordado el contenido de Historia de la Química en versiones y una y dos del libro de texto Química, de la autora Martha Reis, quienes formaron parte del PNLD de los años 2015 y 2018. Para ello, se realizó una Revisión Sistemática de la Literatura para ver qué han argumentado otros investigadores en el campo sobre la importancia de la HQ en la enseñanza de la química, un estudio documental que analiza lo que PCNs, BNCC y PNLD han hablado sobre HQ, y finalmente, un análisis de las dos versiones de los libros de texto descritos anteriormente. Se observó que de una edición a otra, los libros sufrieron algunos cambios, especialmente en los volúmenes dos y tres. Por esta razón, se sugiere que se realicen más estudios en esta área, analizando por encima de todos los demás libros de texto de química.

Palabras clave: Historia de la Química. Enseñanza de la química. Libro de texto. PNLD. Martha Reyes.

\section{ABSTRACT}

Research shows that the curricular reforms that are happening in Brazilian education leave education impoverished, consequently textbooks. Therefore, this article aims to analyze how the content of History of Chemistry has been addressed in versions one and two of 
the textbook Chemistry, by author Martha Reis, which were part of the PNLD of the years 2015 and 2018. For this, a Systematic Literature Review was conducted to see what other researchers in the field have argued about the importance of HQ in chemistry teaching, a documentary study analyzing what PCNs, BNCC and PNLD have talked about hq, and finally, an analysis of the two versions of the textbooks described above. It was observed that from one edition to another, the books underwent some changes, especially in volumes two and three. For this reason, it is suggested that more studies be carried out in this area, analyzing above all other chemistry textbooks.

Keywords: History of Chemistry. Chemistry teaching. Textbook. PNLD. Martha Reis.

\section{INTRODUÇÃO}

Tem-se buscado um meio de fazer com que o aluno consiga aprender o conteúdo de química de modo mais nítido e crítico, para isso é importante ressaltar que a História da Química foi e continua sendo construída pelos homens, gerando a reelaboração de dados e colaborações científicas que aconteceram em diferentes épocas (ROSA; AMARAL; MENDES, 2016, p. 65).

O livro didático é uma ferramenta empregada no ensino para auxiliar no exercício pedagógico do professor, em algumas ocasiões e utilizado como um meio para realizar pesquisas. No ensino de ciências, os livros didáticos compõem artifícios de suma importância, já que em muitos casos, o único material didático à disposição dos professores e alunos (SILVA et al., 2019, p. 163-164).

Contudo, ainda que o livro didático seja pautado como uma necessidade pedagógica, existe conjunto de interesses que circundam todo o Programa Nacional do Livro Didático (PNLD), e que é promovido por grupos econômicos que, através de instruções de organizações ligadas à educação, ou se aproveitando de instituições privadas, articulam os rumos das políticas educacionais (ROCHA; MELLO, 2020, p. 21).

Livros didáticos são mercadorias didático-pedagógicas desenvolvidas tendo como base algum parâmetro teórico-metodológico, no qual conjectura um perfil epistemológico de seus autores, e que são enquadrados no desejo comercial de editoras para que uma determinada freguesia seja atendida (ROCHA; MELLO, 2020, p. 3).

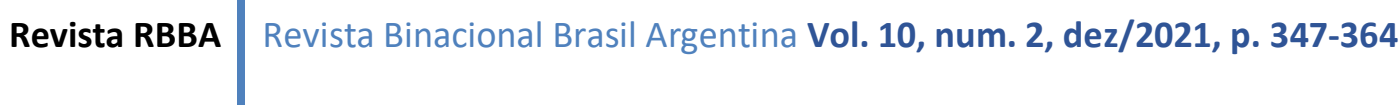


O PNLD, a cada novo governo, passa por reedições, podendo ser ou em seu texto oficial, nos modos de avaliação, nos modelos de materiais ofertados, ou no segmento ideológico que o Ministério da Educação (MEC) tem seguido. Práticas desenvolvidas por empresas privadas sempre estiveram rondando as políticas públicas, fazendo que os seus interesses sejam impostos, em alguns momentos, com menos força, já em outros, de modo bastante agressivo. O programa Todos Pela Educação é um exemplo de o movimento empresarial tem influenciado nas políticas educacionais, nesse momento sobretudo, na elaboração da Base Nacional Comum Curricular (BNCC), que irá impor os conteúdos que os livros didáticos devem conter (ROCHA; MELLO, 2020, p. 21-22).

Diante disso, o presente artigo tem o objetivo de analisar os livros didáticos, denominado Química, da autora Martha Reis, que fizeram parte do PNLD 2015 e 2018, para avaliar se os livros sofreram mudanças no que diz respeito ao seu conteúdo de História da Química.

Para isso foi realizada uma pesquisa de natureza avançada, de caráter descritivo, abordagem qualitativa, onde se desenvolveu um estudo bibliográfico e documental, analisando sobretudo, os principais documentos que tratam sobre o currículo da educação básica e uma observação precisa nos livros didáticos já citados. A fim de obter dados convergentes com as pesquisas já desenvolvidas na área, foi efetuada uma Revisão Sistemática de Literatura sobre a importância da História da Química para o Ensino de Química.

Os resultados obtidos correspondem com a problemática levantada, onde se observou que os livros da autora Martha Reis sofreram alterações entre uma edição e outra, no que se refere ao conteúdo de História da Química.

\section{A importância da História da Ciência e da Química para o Ensino de Química}

O ensino de Química (EQ) consegue englobar diversos meios de realizar interdisciplinaridade com as mais variadas áreas de ensino, tendo a química a sua peculiaridade no que diz respeito a natureza científica, ela passou por vários processos de evolução ao longo dos séculos, desde o descobrimento do fogo, percorrendo a alquimia, até chegar aos dias atuais, a química foi associada principalmente as questões experimentais e aos brilhantes cientistas, como sendo os responsáveis pela sua evolução. Mas quando se refere a abordagem da História da Química (HQ) no ensino básico, é uma área que ainda está estática e possui uma resistência,

Revista RBBA $\mid$ Revista Binacional Brasil Argentina Vol. 10, num. 2, dez/2021, p. 347-364 
em que percebemos serem poucas as informações passadas aos estudantes e com poucas referências ligadas ao contexto histórico (ROSA; AMARAL; MENDES, 2016, p. 59).

A História da Ciência (HC), desde sua institucionalização no início do século XX, compreendeu-se como área de interação entre as ciências naturais e as ciências humanas (BELTRAN, 2013, p. 72). Introduzir a HC no ensino, contribuirá para que os alunos conheçam a ciência de um modo mais atrativo e seja desperto o interesse pelo conhecimento científico, bem como pelas questões que rodeiam a área em estudo. A HC é essencial para evidenciar o ofício da ciência como parte da cultura humana, concentrada no decorrer dos séculos, "cultura esta com a qual a Educação Científica efetivamente emancipadora deve estar sempre preocupada.” (REIS; SILVA; BUZA, 2012, p. 2-3).

Vidal e Porto (2012, p. 295) apontam que a utilização da HC no Ensino de Ciência (EC) fará com que aconteça uma humanização das ciências e poderá ser relacionada aos interesses éticos, políticos e culturais, e que o acréscimo de tal conteúdo ainda deixará as aulas mais estimulantes e reflexivas, fazendo com que os alunos desenvolvam a criticidade; contribuirá para que os conteúdos científicos sejam melhor compreendidos; e melhorará a formação dos professores, colaborando para o avanço de uma epistemologia da ciência mais autêntica na sala de aula.

Reis, Silva e Buza (2012, p. 4) acrescentam argumentando que, a HC colaborará para ocorrer melhorias nas aulas, pois a mesma permite a inserção de conceitos científicos dento de uma realidade humana para ser capaz a construção de fatores relevantes para se trabalhar o conhecimento científico, os interesses políticos e econômicos, além do fato de reconhecer a ciência como uma construção humanística, não apenas revelando as causas positivas, mas também mostrando que a ciência é atingível. Além de que os conceitos científicos sofrem alterações no decorrer dos tempos até que de fato seja consolidado um modelo dominante.

A inclusão da HC no EC, possibilita aos alunos a oportunidade de entender que a Ciência é feita por pessoas - homens e mulheres -, tão reais quanto eles, e que tal construção está ligada a um período histórico-social em que pensamentos filosóficos divergentes predominavam. A inserção da HC no EQ proporciona aos discentes uma visão reflexiva e crítica sobre os conteúdos estudados na disciplina. Desta maneira, ter conhecimento sobre a HC é aprender que incertezas, discussões e motivações conduziram que uma teoria fosse refutada ou aceita, considerando o momento histórico-social que ocorreram (RUSSO; RÔÇAS, 2019, p. 158-160).

Revista RBBA $\mid$ Revista Binacional Brasil Argentina Vol. 10, num. 2, dez/2021, p. 347-364 
Espir, Epoglou e Marques (2019, p. 658) explicam que a HQ pode colaborar para o entendimento de um conceito cientifico e para compreender a própria natureza da ciência, além de fazer com que as aulas de química se tornem mais interessantes e desafiadoras.

Deve-se entender, portanto, que a HC não tomará o lugar do EC que se conhece, mas complementará os conteúdos estudados enfatizando assim o saber científico, pois a ciência não é feita de fatos isolados, mas de uma evolução histórica e cultural da humanidade, por isso devem ser associados ao EQ (ROSA; AMARAL; MENDES, 2016, p. 60).

Corroborando com tal afirmativa, Vidal e Porto (2012, p. 95) explanam que a memorização de conteúdos ocasionará em uma concepção deformada da ciência, e que o ensino sem contextualização, tendo com base apenas a transmissão de conceitos, produzirá uma visão científica socialmente neutra, que deixará as áreas essenciais da ciência e tecnologia obscuras.

A HC preserva importantes manifestações que auxiliará os estudantes a compreenderem e a levarem o conhecimento químico para o seu cotidiano, onde será desperto o interesse pela ciência não apenas para a teoria, mas unindo a teoria e a história (PIRES; ABREU; MESSEDER, 2010, p. 2). Deste modo, a inclusão de questões da HC tem de evidenciar a especificidade da Ciência como um desenvolvimento de construção humana, tal processo "passa pela interação entre homem e fatores sociais, históricos e econômicos, sendo a HQ um fator mediador relevante nesse processo." (ROSA; AMARAL; MENDES, 2016, p. 59-60).

Deste modo, para fazer com que a $\mathrm{HC}$ de forma efetiva colabore para esse processo de aprendizagem da ciência, o docente terá que dispor de materiais de pesquisa que sejam coerentes com seus objetivos, com a intenção de dar suporte no desenvolvimento do ensino (VIDAL; PORTO, 2012, p. 295).

\section{A História da Química nos PCNs, na BNCC e no PNLD}

Os Parâmetros Curriculares Nacionais (PCNs) configuram um referencial de qualidade para a educação básica no Brasil. Seu papel é de direcionar e assegurar a coerência dos investimentos no sistema de educação, nacionalizando debates, estudos e orientações, subsidiando a participação de professores e técnicos brasileiros, sobretudo daqueles que estão mais distantes, que não possuem muito contato com a produção pedagógica. (BRASIL, 1997, p. 13).

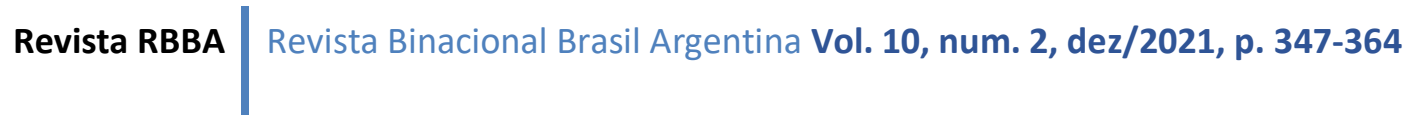


Por sua natureza aberta, configuram uma proposta flexível, a ser concretizada nas decisões regionais e locais sobre currículos e sobre programas de transformação da realidade educacional empreendidos pelas autoridades governamentais, pelas escolas e pelos professores. Não configuram, portanto, um modelo curricular homogêneo e impositivo, que se sobreporia à competência político-executiva dos Estados e Municípios, à diversidade sociocultural das diferentes regiões do País ou à autonomia de professores e equipes pedagógicas (BRASIL, 1997, p. 13).

O Conselho Nacional de Educação (CNE), em 1998, implantou os PCNs, que norteiam e organizam o ensino em quatro áreas de conhecimento: Linguagens, Códigos e suas Tecnologias, Ciências da Natureza e suas Tecnologias e Ciências Humanas e suas Tecnologias, com o propósito de amplificar os conhecimentos associando-os as competências e habilidades a serem desenvolvidas, traçando os conteúdos em uma estrutura interdisciplinar e contextualizada. Nesse panorama em que o estudante é o indivíduo responsável pela sua construção como cidadão e ser social, e na agregação entre as matérias, diversas alterações foram necessárias em relação à abordagem dos conteúdos e o modo com eles precisam ser trabalhados para propiciar uma maneira de aprendizagem justa, e atender as orientações da Lei de Diretrizes e Bases da Educação Nacional (LDB) (ROSA; AMARAL; MENDES, 2016, p. 58). "Entende-se os PCNs como uma espécie de base, pois tal programa dá direções de como os professores devem trabalhar com os seus alunos" (SANTOS FILHO; BARROSO; SAMPAIO, 2021, p. 3).

Os PCNs redirecionaram a educação nacional para a formação cidadã. As novas recomendações proporcionaram alterações no currículo, por conseguinte, nos livros didáticos. As editoras tiveram que se adequar aos novos conceitos teórico-metodológicos forjados em um princípio neoliberal, interessados apenas em formar trabalhadores, mas que os modos de produção precisariam atentar-se às consequências sociais de suas atividades (ROCHA; MELLO, 2020, p. 7).

Os PCNs para o EQ descrevem que, na compreensão do mundo por ferramentas da Química, é de fundamental importância que seja explicitado sua natureza prática. Dessa maneira, o conhecimento químico não tem que ser aprendido como um conjunto de conhecimentos isolados e finalizados, mas como uma evolução da mente humana, que está sempre em contínua transformação (BRASIL, 2000, p. 31). E é neste ponto em que a HQ aparece como sendo "parte do conhecimento socialmente produzido", e que devido a isso, ela deve atravessar todo o EQ, proporcionando ao estudante o entendimento do processo de 
construção desse conhecimento, com seus progressos, falhas e discussões. (BRASIL, 2000, p. $31)$.

Nos PCN+, onde contém as Orientações Educacionais Complementares aos PCNs, é possível analisar a habilidade sobre a: “contextualização sociocultural, ou seja, a inserção do conhecimento disciplinar nos diferentes setores da sociedade, suas relações com os aspectos políticos, econômicos e sociais de cada época e com a tecnologia e cultura contemporâneas." (BRASIL, 2002, p. 88).

Contudo, quando se analisa a fundo os PCN+ de Química, de nove temas trabalhados, apenas na primeira unidade temática do segundo tema, que vai tratar sobre os primeiros modelos de constituição da matéria, é que se observa de forma clara que será trabalhado o conteúdo de HQ, quando o documento expõe a seguinte habilidade: "Compreender os modelos explicativos como construções humanas num dado contexto histórico e social" (BRASIL, 2002, p. 96).

Consegue-se ainda perceber, de forma não tão evidente, um pouco de HQ na primeira unidade temática do terceiro tema, que fala sobre energia e transformação química, quando uma das habilidades elucida que através dela será possível “compreender a evolução das ideias sobre pilhas e eletrólise, reconhecendo as relações entre conhecimento empírico e modelos explicativos." E também na primeira unidade temática do oitavo tema, onde se trabalha a "química e vida: noções básicas sobre evolução da vida; compostos químicos e pré-vida; transformações dos compostos orgânicos através dos tempos" (BRASIL, 2002, p. 98; 104).

A Base Nacional Comum Curricular (BNCC) é um documento normativo que estabelece o conjunto de aprendizagens consideradas essenciais, que todos os estudantes da educação básica devem desenvolver no decorrer dos três níveis de ensino. Seu principal objetivo é ser a norteadora da qualidade da educação básica no país através da instalação de um nível de aprendizagem e desenvolvimento a que todos os estudantes têm direito (BRASIL, 2018, p. 8-9).

Durante toda a educação básica, as aprendizagens essenciais determinadas na BNCC pretendem garantir o desenvolvimento de dez competências gerais, que consolidam, na esfera pedagógica, os direitos de aprendizagem e desenvolvimento (BRASIL, 2018, p. 8).

Na BNCC, competência é definida como a mobilização de conhecimentos (conceitos e procedimentos), habilidades (práticas, cognitivas e socioemocionais), atitudes e valores para resolver demandas complexas da

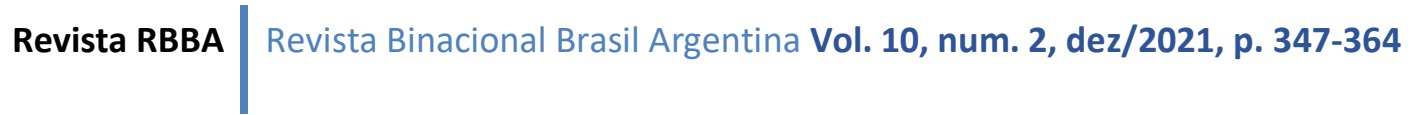


vida cotidiana, do pleno exercício da cidadania e do mundo do trabalho (BRASIL, 2018, p. 8).

A BNCC possui diretrizes invisíveis, como exemplo, pode citar-se os "recursos de forte classificação e fraco enquadramento", que dá indícios de que o objetivo dela é escolher e estruturar no currículo aquilo que estima como essencial e que se estima atribuir um valor de veracidade (SANTOS FILHO; BARROSO; SAMPAIO, 2021, p. 2).

A BNCC (2018, p. 549) explica que a contextualização social, histórica e cultural da ciência e da tecnologia, é necessária para que as competências possam ser entendidas como iniciativas humanas e sociais. Em vista disso, a BNCC pretende também estudar o ofício do conhecimento científico e tecnológico "na organização social, nas questões ambientais, na saúde humana e na formação cultural, ou seja, analisar as relações entre ciência, tecnologia, sociedade e ambiente".

O documento da BNCC (2018, p. 549) descreve ainda que a contextualização histórica não irá se ocupar apenas em citar nome de cientistas e datas importantes para HC, mas, além disso, também explanará os conhecimentos científicos como obras socialmente desenvolvidas, com seus obstáculos e contradições, tendo influência e sendo influenciados por questões políticas, econômicas, tecnológicas, ambientais e sociais de cada localidade, tempo e cultura. A contextualização histórica visa realizar comparações de diferentes argumentos científicos propostos em épocas e culturas distintas, e a reconhecer as limitações explicativas das ciências, fazendo com que possibilidades sejam criadas para que os alunos possam compreender o processo da construção do conhecimento científico.

Quando se faz um estudo das competências específicas da BNCC, percebe-se na competência específica 2, que diz que - vai realizar uma análise e utilizará de leituras sobre a dinâmica da Vida, da Terra e do Cosmos para construir pressupostos, efetuar hipóteses sobre o comportamento e a evolução dos seres vivos do Universo, e respaldar e resguardar medidas éticas e responsáveis. (BRASIL, 2018, p. 556) - a presença do conteúdo de história e filosofia da ciência, "nessa competência específica, podem ser mobilizados conhecimentos conceituais relacionados a: [...] história e filosofia da ciência.” (BRASIL, 2018, p. 556).

O Programa Nacional do Livro e do Material Didático (PNLD) é destinado a qualificar e a tornar acessível obras didáticas, pedagógicas e literárias, além de outros materiais, que dão suporte a prática educativa, de modo sistemático, regular e gratuito, “às escolas públicas de educação básica das redes federal, estaduais, municipais e distrital e às instituições

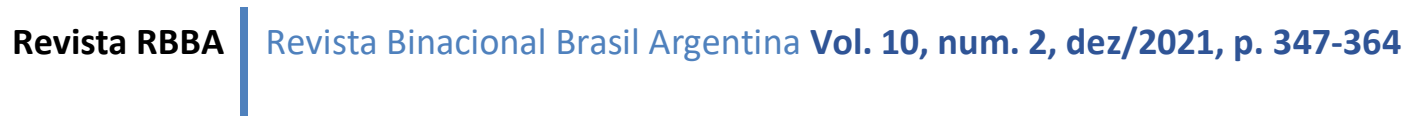


comunitárias, confessionais ou filantrópicas sem fins lucrativos e conveniadas com o Poder Público." Um dos principais objetivos do PNLD é dar apoio a implementação da BNCC. (BRASIL, 2017).

O Programa Nacional do Livro Didático (PNLD) surgiu como uma estratégia de apoio à política educacional criada pelo Estado brasileiro em 1985, em substituição ao Programa do Livro Didático para o Ensino Fundamental (PLDEF) de 1971. Em 2003 foi criado o Programa Nacional do livro Didático para o Ensino Médio (PNLEM), objetivando a distribuição de livros didáticos a todos os alunos da rede pública matriculados no ensino médio (ROSA; AMARAL; MENDES, 2016, p. 58-59).

A implantação do PNLEM foi uma decisão política significativa. Foi considerado uma decisão importante, devido ter sido a primeira vez na história do Brasil em que a escolha do livro didático do ensino médio foi orientada por diretrizes político-pedagógicas, e não apenas manipulada pelo mercado editorial (ECHEVERRIA; MELLO; GAUCHE, 2012, p. 63-64).

O PNLD, como política pública, orienta e instiga a produção de livros didáticos. Esta é a fala governamental reproduzida nos documentos expedidos a cada seleção pública, sobretudo através dos editais. Anualmente, o edital é reformulado para satisfazer a necessidade das séries que vão receber o material, devido a isso, novos comitês de avaliação são determinados, fazendo com que aja alternância das obras que são concedidas para a escola pública (ROCHA; MELLO, 2020, p. 21).

A guia do PNLD de Química (2017, p. 12) descreve que a HQ contribui para haver uma melhor concepção da natureza da ciência, da ligação dos cientistas com a formação do conhecimento químico, dos impactos políticos para o avanço da Química e para compreender a produção coletiva da ciência e de sua transitoriedade. A guia ainda acrescenta argumentando que, a HQ cooperará para um melhor entendimento da natureza da ciência se considerar: a participação da mulher no desenvolvimento do conhecimento científico, a confrontação ao pensamento da ciência como produção individual, a variabilidade dos modelos explicativos, o reconhecimento do progresso científico em outras sociedades além da europeia, a contribuição de diferentes grupos étnicos na evolução dos saberes, dentre outros.

Diversas histórias descritas nos livros didáticos de Química mais antigos cooperaram para serem criados estereótipos sobre esta ciência, e não levaram aos estudantes a entenderem a sua importância para o desenvolvimento científico. Mas, os livros atuais têm procurado 
difundir a HC a partir de circunstâncias que considerem a diversidade e a pluralidade do desenvolvimento da Química na sociedade (BRASIL, 2017, p. 12).

\section{Metodologia}

O presente artigo é de caráter qualitativo, exploratório, bibliográfico e documental.

Pesquisas exploratórias têm a finalidade de garantir que ocorra uma maior proximidade com o problema, com o objetivo de torná-lo mais esclarecedor ou a criar hipóteses (GIL, 2002, p. 41). A pesquisa bibliográfica é aquela sendo realizada a partir de fontes já existentes, decorrentes de pesquisas anteriores. Já a pesquisa documental, tem como principal referência, documentos advindos de diversas fontes, podendo ser documentos oficiais, jornais, imagens, gravações (SEVERINO, 2017).

Para a construção do referencial teórico deste artigo, foi realizado uma Revisão Sistemática de Literatura, utilizando o Portal de Periódicos da Capes (http://www.periodicos.capes.gov.br). Através do mecanismo de "Busca Avançada", foi delimitando o resultado das pesquisas para apenas artigos científicos, publicados entre o período de 2010 a 2020, com presença dos descritores "História da Química" AND "Livro Didático" no título (FEITOSA, 2021). Para a pesquisa documental foi efetuado uma busca sobre o que os PCNs, a BNCC e o PNLD descrevem sobre o conteúdo de História da Química.

Este trabalho investiga a presença dos conteúdos de História da Química nos livros didáticos da autora Martha Reis, denominado Química, cujos volumes são 1, 2 e 3, da editora Ática, $1^{\circ}$ e $2^{\circ}$ edição. A primeira edição fez parte do PNLD de 2015, já a segunda, do PNLD de 2018.

Para a escolha dos livros, foi considerado serem da mesma autora e de PNLDs de anos diferentes, para poder avaliar se após uma edição ou outra do PNLD houve uma melhoria, uma piora ou não sofreu nenhuma alteração no que diz respeito aos conteúdos de História da Química.

Esta analise tomou como referência as categorias elaboradas por Silva e Teixeira (2009), que apresentou a seguinte tabela como modelo:

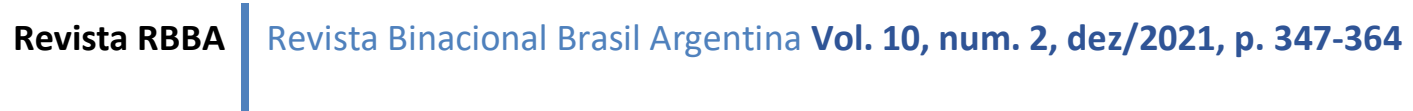


Tabela 1 - Categorias de Análise

\begin{tabular}{|c|c|c|}
\hline Categoria & Subcategoria & Definição \\
\hline \multirow{4}{*}{$\begin{array}{l}\text { (1) Em relação à } \\
\text { quantidade de } \\
\text { conteúdo histórico }\end{array}$} & (1.1) Não há conteúdo histórico. & $\begin{array}{l}\text { História da ciência não foi em } \\
\text { nenhum momento abordada. }\end{array}$ \\
\hline & $\begin{array}{l}\text { (1.2) Há conteúdo histórico, mas } \\
\text { de maneira espaçada ou } \\
\text { incompleta. }\end{array}$ & $\begin{array}{l}\text { A História da Ciência aparece } \\
\text { somente como introdução de } \\
\text { capítulos ou assuntos ou com } \\
\text { informações imprecisas e } \\
\text { incompletas, como, por exemplo, } \\
\text { sem a devida localização } \\
\text { temporal. }\end{array}$ \\
\hline & $\begin{array}{l}\text { (1.3) Há conteúdo histórico, mas } \\
\text { em quantidade pequena. }\end{array}$ & $\begin{array}{l}\text { A História da Ciência aparece } \\
\text { introduzindo assuntos ou } \\
\text { capítulos, mas sem riqueza de } \\
\text { detalhes. }\end{array}$ \\
\hline & $\begin{array}{l}\text { (1.4) Há uma grande quantidade de } \\
\text { conteúdo histórico. }\end{array}$ & $\begin{array}{l}\text { A História da Ciência, além de } \\
\text { fazer introdução ao capítulo ou } \\
\text { assunto, está presente ao longo } \\
\text { do texto. }\end{array}$ \\
\hline \multirow{4}{*}{$\begin{array}{l}\text { (2) Em relação à } \\
\text { maneira como esses } \\
\text { tópicos foram } \\
\text { abordados }\end{array}$} & $\begin{array}{c}\text { (2.1) “Boxes” ou seções } \\
\text { específicas sobre história da } \\
\text { ciência. }\end{array}$ & $\begin{array}{c}\text { Biografias de cientistas e/ou fatos } \\
\text { relacionados a alguma descoberta } \\
\text { científica. }\end{array}$ \\
\hline & $\begin{array}{l}\text { (2.2) O conteúdo histórico está } \\
\text { presente diluído nos capítulos, mas } \\
\text { de forma pontual. }\end{array}$ & $\begin{array}{c}\text { O conteúdo histórico está } \\
\text { inserido no texto, mas serve } \\
\text { apenas como introdução a ele. }\end{array}$ \\
\hline & $\begin{array}{l}\text { (2.3) O conteúdo histórico está } \\
\text { presente diluído nos capítulos e de } \\
\text { forma articulada }\end{array}$ & $\begin{array}{c}\text { O conteúdo histórico está } \\
\text { inserido no texto dialogando com } \\
\text { o conteúdo específico. }\end{array}$ \\
\hline & $\begin{array}{l}\text { (2.4) Capítulo específico sobre } \\
\text { História da Ciência }\end{array}$ & $\begin{array}{c}\text { Capítulos inteiros destinados à } \\
\text { História da Ciência. }\end{array}$ \\
\hline \multirow{4}{*}{$\begin{array}{c}\text { (3) Em relação à } \\
\text { qualidade das } \\
\text { informações } \\
\text { históricas } \\
\text { apresentadas }\end{array}$} & $\begin{array}{c}\text { (3.1) Presença de mitos científicos } \\
\text { ou presença de erros }\end{array}$ & $\begin{array}{l}\text { Histórias não comprovadas ou } \\
\text { fictícias, ou informações } \\
\text { imprecisas ou com equívocos. }\end{array}$ \\
\hline & $\begin{array}{l}\text { (3.2) Análise equivocada de } \\
\text { eventos históricos sob a ótica dos } \\
\text { conceitos atuais }\end{array}$ & $\begin{array}{l}\text { Apropriação inadequada de } \\
\text { termos e conceitos atuais para } \\
\text { discutir a história da ciência. }\end{array}$ \\
\hline & $\begin{array}{l}\text { (3.3) Conteúdo histórico não } \\
\text { satisfaz }\end{array}$ & $\begin{array}{c}\text { As informações históricas não } \\
\text { valorizam a Ciência com relação } \\
\text { ao ensino. }\end{array}$ \\
\hline & $\begin{array}{c}\text { (3.4) O conteúdo histórico } \\
\text { complementa os conteúdos dos } \\
\text { Livros Didáticos }\end{array}$ & $\begin{array}{l}\text { Baseado apenas em fatos } \\
\text { historicamente comprovados e } \\
\text { que ilustram a forma pela qual a } \\
\text { ciência se desenvolve na prática. }\end{array}$ \\
\hline
\end{tabular}




\section{Resultados e Discussões}

\subsection{Livro didático da Martha Reis no PNLD 2015}

Conforme a guia de Química do PNLD (2014, p. 31), esta edição do livro da Martha Reis (2013) supera concepções do EQ organizados apenas em regras, nomenclatura e resoluções de questões de ENEM ou vestibulares. Desse modo, a coleção favorece o estudante, no sentido de propiciar maiores possibilidades de debater sobre questões que trabalham com CTSA (ciência, tecnologia, sociedade e ambiente).

Nos três volumes consideram-se relações entre conhecimentos CTSA. Os textos apresentados permitem que aconteça uma contextualização dos conceitos químicos, através de uma metodologia clara e objetiva, que valoriza os conhecimentos prévios dos estudantes e propõe atividades de discussão e trabalho em grupo (BRASIL, 2015, p. 31).

Ao se analisar a guia a fundo, percebe-se que em um único momento se fala sobre algo relacionado a HQ quando descrevem: “A seção 'Curiosidade' relata fatos intrigantes, dados históricos ou informações complementares aos conteúdos abordados, com vistas a enriquecer a aprendizagem." (BRASIL, 2014, p. 32).

\subsection{Análise do conteúdo de História da Química nos três volumes do livro da Martha} Reis (2013)

Tabela 2 - Análise das obras e classificação de acordo com as categorias da Tabela 1

\begin{tabular}{|c|c|c|c|c|c|c|c|c|c|c|c|c|}
\hline Categorias & \multicolumn{3}{|c|}{$\begin{array}{c}\text { 1 - Em relação à } \\
\text { quantidade de conteúdo } \\
\text { histórico }\end{array}$} & \multicolumn{3}{c|}{$\begin{array}{c}\text { 2- Em relação à maneira } \\
\text { como esses tópicos foram } \\
\text { abordados }\end{array}$} & \multicolumn{3}{c|}{$\begin{array}{c}\text { Em relação à quantidade } \\
\text { de informações } \\
\text { apresentadas }\end{array}$} \\
\hline Subcategorias & $\mathbf{1 . 1}$ & $\mathbf{1 . 2}$ & $\mathbf{1 . 3}$ & $\mathbf{1 . 4}$ & $\mathbf{2 . 1}$ & $\mathbf{2 . 2}$ & $\mathbf{2 . 3}$ & $\mathbf{2 . 4}$ & $\mathbf{3 . 1}$ & $\mathbf{3 . 2}$ & $\mathbf{3 . 3}$ & $\mathbf{3 . 4}$ \\
\hline Volume 1 & & & $\mathrm{X}$ & $\mathrm{X}$ & $\mathrm{X}$ & & $\mathrm{X}$ & & & & & $\mathrm{X}$ \\
\hline Volume 2 & & $\mathrm{X}$ & $\mathrm{X}$ & & $\mathrm{X}$ & & & & & & $\mathrm{X}$ & \\
\hline Volume 3 & & $\mathrm{X}$ & $\mathrm{X}$ & & $\mathrm{X}$ & $\mathrm{X}$ & & & & & $\mathrm{X}$ & \\
\hline
\end{tabular}

Fonte: elaborada pelos autores, 2021

\subsection{Livro didático da Martha Reis no PNLD 2018}

Segundo a guia de Química do PNLD (2017, p. 26), esta edição considera necessário a contextualização, seja ela histórica e social, do conhecimento químico. O documento acrescenta descrevendo que esta obra consegue reunir características desejáveis para o desenvolvimento do currículo de Química, como: 
promoção adequada da natureza do conhecimento científico, abordagem da dimensão ambiental dos problemas contemporâneos, contextualização dos conceitos químicos em diferentes situações da vivência cotidiana, apresentação de imagens e figuras que colaboram para o ensino dos conteúdos, articulação dos códigos próprios da Química com os campos teórico e empírico dos fenômenos (BRASIL, 2017, p. 26).

Ao realizar uma análise aprofundada, é encontrado na guia, dois momentos sendo destacada uma fala sobre a HQ. A guia descreve que no livro, na seção Curiosidade, são trazidas temáticas gerais, dentre as quais destaca-se "dados históricos e informações complementares ao tema central." (BRASIL, 2017, p. 27). Em outra parte do documento, destaca-se que: "com relação ao conhecimento químico, a obra se preocupa em dispor os conceitos tomando-se em consideração o seu desenvolvimento histórico.” (BRASIL, 2017, p. 28).

\subsection{Análise do conteúdo de História da Química nos três volumes do livro da Martha Reis (2016)}

Tabela 3 - Análise das obras e classificação de acordo com as categorias da Tabela 1

\begin{tabular}{|c|c|c|c|c|c|c|c|c|c|c|c|c|}
\hline \multirow{2}{*}{$\begin{array}{c}\text { Categorias } \\
\text { Subcategorias } \\
\end{array}$} & \multicolumn{4}{|c|}{$\begin{array}{c}1 \text { - Em relação à } \\
\text { quantidade de conteúdo } \\
\text { histórico }\end{array}$} & \multicolumn{4}{|c|}{$\begin{array}{c}2 \text { - Em relação à maneira } \\
\text { como esses tópicos foram } \\
\text { abordados }\end{array}$} & \multicolumn{4}{|c|}{$\begin{array}{l}\text { Em relação à } \\
\text { quantidade de } \\
\text { informações } \\
\text { apresentadas }\end{array}$} \\
\hline & 1.1 & 1.2 & 1.3 & 1.4 & 2.1 & 2.2 & 2.3 & 2.4 & 3.1 & 3.2 & 3.3 & 3.4 \\
\hline Volume 1 & & $\mathbf{X}$ & $\mathbf{X}$ & & $\mathbf{X}$ & $\mathbf{X}$ & & & & & & \\
\hline Volume 2 & & $\mathbf{X}$ & $\mathbf{X}$ & & $\mathbf{X}$ & & & & & & $\mathbf{X}$ & \\
\hline Volume 3 & & $\mathbf{X}$ & $\mathbf{X}$ & & $\mathbf{X}$ & $\mathbf{X}$ & & & & & $\mathbf{X}$ & \\
\hline
\end{tabular}

Fonte: elaborada pelos autores, 2021

\subsection{Comparação entre as duas edições}

Ao analisar às duas tabelas apresentadas acima, percebe-se que no volume 1 da primeira edição, existe uma maior presença do conteúdo de HQ. Nos volumes 2 e 3, tanto da primeira como da segunda edição, verifica-se que não houve muita mudança de uma edição para outra.

Considerando o que a guia do PNLD apresentava, o que era esperado é que na última edição existisse uma maior presença da HQ, porém, o que é observado é que aconteceu o contrário, na primeira edição o conteúdo de HQé mais presente que na segunda, principalmente quando é feito uma comparação entre os dois volumes 1 .

Outro ponto semelhante nas duas edições, é que conforme as tabelas criadas, as subcategorias 1.1, 2.4, 3.1 e 3.3 não foram marcadas em nenhum dos volumes. Logo, se explica que em todos os volumes apresentam conteúdos históricos, mesmo que sua presença seja 
mínima, e que em nenhum momento os fatos históricos destacados possuíam dados imprecisos ou equivocados e que não houve uma apropriação inadequada de termos e conceitos químicos atuais para se debater sobre a HC. Contudo, mesmo que o que foi descrito anteriormente seja algo positivo, a subcategoria 2.4 analisa a presença de capítulos inteiros destinados à $\mathrm{HC}$, e o que se nota, e que já era de se esperar, é que em nenhum dos volumes isso acontece, e que apenas no volume um da primeira edição, o conteúdo de HQ está inserido no texto de forma articulada com o conteúdo específico.

\section{Considerações Finais}

A maioria das editoras utiliza de truques gráficos para se moldarem aos novos documentos. Todavia, no decorrer dos anos e agora com as avaliações trienais, livros didáticos de Química com grande respaldo no mercado foram sendo reprovados nos editais do MEC, fazendo com que houvesse mudança no conteúdo, nas propostas didático-pedagógicas, dentre outras questões (ROCHA; MELLO, 2020, p. 8). Tal afirmativa é bastante presente nos livros da Martha Reis, é perceptível estes truques gráficos e essas adaptações nos conteúdos, para que seus livros sejam aceites pelo MEC. Tanto é, que a segunda edição, mesmo possuindo bastante semelhança com a primeira, teve seus conteúdos de HQ mais esvaziados.

Os livros didáticos apresentam o conteúdo de HQ apenas como se estivessem ali para ocupar páginas, não proporcionando que o aluno consiga descobrir os conceitos científicos através do pensamento do cientista. A abordagem da HQ é fundamental para a assimilação de teorias, e deve ser incluído os contextos históricos, onde os conceitos químicos foram desenvolvidos e substituídos por outras descobertas. Compreende-se, desse modo, que a HQ pode auxiliar os estudantes no entendimento da natureza da ciência e no aprendizado de concepções que explicam os fenômenos químicos abordados na disciplina de Química.

A HQ possui uma função significativa para que os conteúdos da disciplina de Química sejam aprendidos. A HQ coopera para a aprendizagem da ciência que ainda é pouco compreendida pelos alunos, podendo também, contribuir com a prática docente, visto que o professor também utiliza os livros didáticos nas elaborações de suas aulas.

Assim sendo, devem ser desenvolvidos mais trabalhos sobre a História da Ciência, nas áreas além da Química, por exemplo, na Física e na Biologia, e também que sejam realizadas outras análises de livros didáticos de química de outros autores, para ver como os mesmos adotam o conteúdo de HQ em suas obras. Sugestiona-se também, mais pesquisas nos Revista RBBA $\mid$ Revista Binacional Brasil Argentina Vol. 10, num. 2, dez/2021, p. 347-364 
documentos que regem o currículo educacional para ver como que eles passarão a exigir uma maior presença da $\mathrm{HC}$ no currículo.

\section{REFERÊNCIAS}

BELTRAN, Maria Helena Roxo. História da Química e Ensino : estabelecendo interfaces entre campos interdisciplinares. Abakós, vol. 1, no. 2, p. 67-77, 2013.

BRASIL. Decreto $\mathbf{n}^{\mathbf{0}}$ 9.099, de 18 de julho de 2017. Dispõe sobre o Programa Nacional do Livro e do Material Didático. Disponível em: http://www.planalto.gov.br/ccivil_03/_ato20152018/2017/decreto/D9099.htm

BRASIL. Ministério da Educação. Base Nacional Comum Curricular: educação é a base. Brasília: $\quad$ MEC, 2018. Disponível em: http://basenacionalcomum.mec.gov.br/images/BNCC_EI_EF_110518_versaofinal_site.pdf

BRASIL. Ministério da Educação. Guia de livros didáticos: PNLD 2015: química: ensino médio. Brasília: MEC/ SEB, 2014. Disponível em: http://www.fnde.gov.br/phocadownload/programas/Livro_Didatico_PNLD/Guias/PNLD_201 5/pnld_2015_quimica.pdf

BRASIL. Ministério da Educação. Guia de livros didáticos: PNLD 2018: química: ensino médio. Brasília: MEC/ SEB, 2017.

BRASIL. Ministério da Educação. Parâmetros curriculares nacionais: introdução aos parâmetros curriculares nacionais. Brasília: MEC/SEF, 1997. Disponível em: http://portal.mec.gov.br/seb/arquivos/pdf/livro01.pdf

BRASIL. Ministério da Educação. Parâmetros curriculares nacionais do ensino médio: ciências da natureza, matemática e suas tecnologias. Brasília: MEC/ SEMT, 2000. Disponível em: http://portal.mec.gov.br/seb/arquivos/pdf/ciencian.pdf

BRASIL. Ministério da Educação. PCN+ ensino médio: orientações educacionais complementares aos parâmetros curriculares nacionais. Ciências da natureza, matemática e suas tecnologias. Brasília: $\quad$ MEC, 2002. Disponível em: http://portal.mec.gov.br/seb/arquivos/pdf/CienciasNatureza.pdf

ECHEVERRIA, A; MELLO, I. R.; GAUCHE, R. O Programa Nacional do Livro Didático de Química no contexto da educação brasileira. In: ROSA, M. I. P.; ROSSI, A. V. (org.). Educação Química no Brasil: memórias, políticas e tendências. 2. ed. Campinas, SP: Editora Átomo, 2012. p. 63-83.

ESPIR, Iago Ferreira; EPOGLOU, Alexandra; MARQUES, Deividi Marcio. O Uso da História da Química no Ensino de Química: A Visão de Licenciandos em Química. História da Ciência e Ensino: construindo interfaces, vol. 20, p. 657-671, 2019. https://doi.org/10.23925/21782911.2019v20espp657-671 
FEITOSA, Raphael Alves. Uma revisão sistemática da literatura sobre pesquisas na interface ciência e arte. Revista Prática Docente, v. 6, n. 1, e007, 2021. Disponível em: http://periodicos.cfs.ifmt.edu.br/periodicos/index.php/rpd/article/view/987/448

FONSECA, Martha Reis Marque da. Química. 1. ed. São Paulo: Ática, 2013. 3v.

FONSECA, Martha Reis Marque da. Química. 2. ed. São Paulo: Ática, 2016. 3v.

GIL, Antonio Carlos. Como elaborar projetos de pesquisa. 4. ed. São Paulo: Atlas, 2002.

PIRES, Romulo De Oliveira; ABREU, Thais Costa De; MESSEDER, Jorge Cardoso. Proposta de ensino de química com uma abordagem contextualizada através da história da ciência. Ciência em Tela, vol. 3, no. 1, p. 1-10, 2010.

REIS, André Silva; BRITO SILVA, Maria Dulcimar; BUZA, Ruth Gabriel Canga. O uso da história da ciência como estratégia metodológica para a aprendizagem do ensino de química e biologia na visão dos professores do ensino médio. História da Ciência e Ensino: construindo interfaces, v. 5, p. 1-12, 2012.

ROCHA, Edimarcio Francisco; MELLO, Irene Cristina. A Política do PNLD sob a Ótica de Grupos Econômicos: em Foco, a Produção de Livros Didáticos Digitais de Química. Revista da Sociedade Brasileira de Ensino de Química, v. 1, n. 1, p. e012002-e012002, 2020.

ROSA, D. L.; AMARAL, A. M.; MENDES, A. N.F. História Da Química Na Educação Básica : Uma Investigação Nos Livros Didáticos. Revista Conhecimento Online, vol. 1, no. 8, p. 5767, 2016.

RUSSO, Ana Lúcia Rodrigues Gama; RÒÇAS, Giselle. Analisando as dissertações e teses da área de ensino na perspectiva da história e da filosofia da ciência no ensino de química. Alexandria: Revista de Educação em Ciência e Tecnologia, v. 12, n. 1, p. 157-180, 2019.

SANTOS FILHO, Antônio de Pádua Arruda dos; BARROSO, Maria Cleide da Silva; SAMPAIO, Caroline de Goes. História da educação no Brasil: da Constituição Federativa de 1988 a Base Nacional Comum Curricular (BNCC). Research, Society and Development, vol. 10, no. 3, p. e53910313667, 2021. https://doi.org/10.33448/rsd-v10i3.13667.

SEVERINO, Antônio Joaquim. Metodologia do trabalho científico. 2. ed. São Paulo: Cortez, 2017.

SILVA, Erman Naum; TEIXEIRA, Ricardo Roberto Plaza. A história da ciência nos livros didáticos de física. Revista Tecnologia e Tendências, v. 8, n. 1, p. 9-20, 2009. Disponível em: https://periodicos.feevale.br/seer/index.php/revistatecnologiaetendencias/article/view/1443.

SILVA, Nathânia Oliveira; XAVIER, Maria Jaqueline de Miranda Souza; SOUZA, Gahelyka Aghta Pantano. História da química uma proposta de ensino nos livros didáticos. Scientia Naturalis, v. 1, n. 1, 2019.

Revista RBBA $\mid$ Revista Binacional Brasil Argentina Vol. 10, num. 2, dez/2021, p. 347-364 
CONTEÚDO NOS PNLDS DE 2015 E 2018

VIDAL, Paulo Henrique Oliveira; PORTO, Paulo Alves. A história da ciência nos livros didáticos de química do PNLEM 2007. Ciência \& Educação (Bauru), vol. 18, no. 2, p. 291308, 2012. https://doi.org/10.1590/s1516-73132012000200004. 